\title{
Evolution of the corpus luteum volume determined Uultrasonographically and its relation to the plasma progesterone concentration after artificial insemination in pregnant and non-pregnant dairy cows
}

C. Gómez-Seco, 1 ,*

Emailcgoms@unileon.es

B. Alegre, 1

F. Martínez-Pastor, ${ }^{2}$

J. G. Prieto, ${ }^{3}$

J. R. González-Montaña, 1

M. E. Alonso, 4

J. C. Domínguez, 1

1 Department of Medicine, Surgery and Veterinary Anatomy, University of León, Campus de Vegazana s/n, 24071 León, Spain

2 INDEGSAL and Department of Molecular Biology (Cell Biology), University of León, León, Spain

3 Department of Biomedical Sciences, University of León, León, Spain

4 Department of Animal Production, University of León, León, Spain

\section{Abstract}

The aim of this study was to assess the relationship of the evolution of the corpus luteum (CL) volume that was determined ultrasonographically with the pregnancy status in lactating dairy cows during early pregnancy. Ultrasound examinations were carried out on 76 cows following artificial insemination (AI). Plasma concentrations of progesterone were determined from blood samples collected at each ultrasound examination. Conception was confirmed by ultrasonography on day 30 after AI. Around day 14 post-insemination (p.i.), the CL volume tended to decrease in pregnant and non-pregnant cows, and, after day 19 p.i., both groups differed significantly, indicating the luteal regression in non-pregnant cows. Reaching signification on day 20. The diminution in CL volume was also reflected in the plasma progesterone concentration. However, the patterns of $\mathrm{CL}$ volume, estimated by ultrasonography, differed more evidently and earlier between both groups (around 1 week p.i., at day 9 p.i. $P<0.05$, whereas progesterone started to differ around 2 weeks p.i., at day 14 p.i, $P<0.05)$. These results indicate that the estimation of the CL volume by ultrasonography 
could be useful for assessing the presence of a functional CL.

\section{Keywords}
Ultrasound
Corpus luteum
Progesterone
Pregnancy
Dairy cattle
Abbreviations
CL Corpus luteum
$\mathrm{P}_{4} \quad$ Progesterone
AI Artificial insemination
p.i. Post-insemination
P Pregnant
NP Non-pregnant
PPV Positive predictive value
NPV Negative predictive value
$\mathrm{PGF}_{2 \alpha}$ Prostaglandin $\mathrm{F}_{2 \alpha}=$

\section{Introduction}

Many research findings in large animal reproduction during the past 30 years can be credited entirely to ultrasonic imaging (Ginther 2014). This technology has played a key role in reproductive management of cattle, since it allows visualize the ovarian and uterine structures or the pregnancy status and fetal viability (Fricke 2002).

The corpus luteum (CL) is a transient endocrine organ in the mammalian ovary. The main function of the CL is to produce the steroid hormone progesterone, which is necessary for the establishing and maintaining pregnancy in all domestic animals, including cattle (Bazer et al. 2010). Depending on the species, CL may produce other hormones such as oxytocin, noradrenaline and growth factors efficiently stimulate progesterone synthesis in bovine early CL (Niswender et al. 2000).

If pregnancy does not occur, the CL regresses during luteolysis. Prostaglandin $\mathrm{F}_{2 \alpha}$ from the uterus exerts a luteolytic effect on the $\mathrm{CL}$, and the plasma concentration of progesterone decreases (Ginther et al. 2010). However, when pregnancy is established, the CL lifespan is prolonged, and in cows, the CL continues to produce progesterone during the gestation period (Niswender et al. 2000). The early identification of non-pregnant dairy cows has a direct effect on the calving to conception interval (Stevenson et al. 2003) and increasing artificial insemination service rate (Fricke 2002).

Thus, the correct diagnosis of CL presence and estimation of its functional status are important for the successful management of the reproductive activity of dairy cows (e.g., presence of a CL before the initiation of synchronization program affects fertility) (Galvão et al. 2007). For several years, progesterone in milk or blood has been recognized as a valid indicator of different 
reproductive stages in cows (Waldmann and Raud 2016; Wilsdorf et al. 2016). However, progesterone determinations require specific equipment, methods and time (Simersky et al. 2007; Zia et al. 2012).

Under field conditions, the functional status of a CL is determined by transrectal palpation, which is based on a sensitivity and specificity of the method to identify CL of $86.2 \%$ and $70.3 \%$ (Zdunczyk et al. 2009). However, the presence of a CL is usually easier to diagnose than the absence of a CL (Hanzen et al. 2000). Moreover, the sensitivity of palpation for identifying changes during the luteal evolution is low (e.g. during the regression of the CL, the positive predictive value of the detection by palpation is only 64\%) (Pieterse et al. 1990).

The application of ultrasound scans offers a great opportunity in bovine reproduction for a more reliable CL diagnosis. Ultrasound characteristics of the uterus and CL have been assessed as possible markers for early pregnancy diagnosis (Herzog et al. 2011; Scully et al. 2015). In practice, pregnancy diagnosis involves examination of the entire reproductive tract and even when an embryonic heartbeat is detected, it is recommended to assess the ovaries for the presence of a CL (López-Gatius and García-Ispierto 2010). Literature reviews concluded that the positive predictive value (PPV) and the negative predictive value (NPV) of ultrasonography were greater than the transrectal palpation for detection of a CL (Hanzen et al. 2000).

A number of studies have found a significant relationship between CL size and plasma progesterone during CL-development (Assey et al. 1993; Spell et al. 2001). On the ovulation day, plasma progesterone levels are below the sensitivity of the assay $(<0.50 \mathrm{ng} / \mathrm{dl})$, while the old corpus luteum was still detectable by an ultrasound, having an area of $1.5-2 \mathrm{~cm}^{2}$ and an estimated volume of 1.38-2.13 $\mathrm{ml}$ in non-pregnant cows (Kamimura et al. 1993).

Simultaneously to the enlargement of CL, plasma progesterone levels increased similarly during the luteal phase of growth until day 8 of the cycle (Mann 2009). However, this relationship decreased during the luteal regression phase, in which the luteal volume decreased more slowly in relation to the concentration of progesterone (Kamimura et al. 1993), and the size of the CL is no longer of importance in determining circulating progesterone concentrations (Mann 2009).

Therefore, in this study we aimed at investigating the relationship between CL size as determined by ultrasound scan and progesterone concentrations, in order to contribute to the development of a quick and reliable method to predict pregnancy status in lactating dairy cows.

\section{Material and methods}

\section{Animals}

This study was carried out with 76 clinically and gynecologically healthy lactating Holstein Friesian cows. These cows were (mean \pm SD) $4.0 \pm 0.8$ years old, with a body condition score of $2.9 \pm 0.3$ (scale 1-5), and all of them had given birth at least once. The herds were kept in an intensive system in two commercial farms in León (Spain). The cows were housed indoors, fed a total mixed ration and had free access to water.

Cows did not receive an ovulation synchronization program and checked for signs of estrus with twice-daily transrectal ultrasonography. Every cow was artificially inseminated $12 \mathrm{~h}$ after the detection of first standing estrus with frozen thawed sperm from an artificial insemination bull proven fertility, and examined (ultrasound scanner and plasma progesterone analysis) every 
$24 \mathrm{~h}$, until the pregnancy was confirmed by an ultrasound exam on day 30 post-insemination. After pregnancy diagnosis, cows were retrospectively allocated as being pregnant $(n=33)$ or non-pregnant $(n=43)$.

\section{Ultrasonography}

Ultrasound scans were performed every $24 \mathrm{~h}$ in the mornings by the same operator using a 7.5 MHz linear transducer (Easi-Scan ${ }^{\circledR}$ portable ultrasound, BCF Technology Ltd., Livingston, UK). Three cross-sectional images of the CL were recorded and digitized. In a CL with cavity, area of the CL cavity was assessed separately and subtracted from the total CL area.

To calculate the volume of the corpus luteum $\left(\mathrm{mm}^{3}\right)$ the following equation was applied (Kamimura et al. 1993):

$$
\mathrm{CL} \text { volume }=\frac{\frac{4}{3} \times \text { maximum spheroidal area } \times\left(\frac{\text { height of } \mathrm{CL}}{2}+\frac{\text { width of } \mathrm{CL}}{2}\right)}{2}
$$

\section{Progesterone analysis}

Immediately after the ultrasound examination, blood samples were collected for plasma progesterone concentration analysis. Blood samples $(5 \mathrm{ml})$ were extracted from the coccygeal vessels in Vacutainer ${ }^{\circledR}$ vacuum tubes (Becton Dickinson, Rutherford, NJ) with heparin as an anticoagulant and using sterile needles. Then, the samples were centrifuged at $2200 \mathrm{x} g$ for 10 min (Sigma 2-15 centrifuge, Sigma, Osterode, Germany). The plasma was extracted with a single use pipette and frozen at $-20{ }^{\circ} \mathrm{C}$ in microfuge tubes. The Progesterona Spectria ${ }^{\circledR}$ radioimmunoassay kit (Orion Diagnostic Corp. Espoo, Finland) was used for determinations of plasma progesterone. Sensitivity, inter- and intra-assay variation coefficients were $0.5 \mathrm{pg}-/-\mathrm{ml}$, 9.7 and $5.0 \%$, respectively. The result of progesterone concentrations is expressed in $\mathrm{ng} / \mathrm{ml}$.

\section{Statistical analysis}

For the statistical study, the statistical package Statistic Analysis System Version 6.12 (SAS Institute Inc., Cary, NC, USA) was used. Descriptive statistics were performed and data was presented as mean \pm SEM. The correlation between the volume of the CL and the plasma progesterone concentration was quantified by Pearson correlation coefficients $(P<0.001$ for significance). Since some authors (Kamimura et al. 1993) have suggested that there were high correlations during the first part of the cycle, we also split the time series, in order to determine if correlations varied between the first and second part of the cycle, we have studied the correlations from day 0 to 11 and from day 12 to 22 . Moreover, we also studied from day 0 to 17 and from day 18 to 22, because the luteal regression in non-pregnant cows starts by day 17 . Correlation coefficients were classified as strong $(r>0.7)$, moderate $(0.3<r<0.7)$ or weak $(r<0.3)$ respectively. ANOVA was used to study the variability due to different days along the cycle and between pregnant and non-pregnant cows $(P<0.05)$.

\section{Results}

The comparison of the corpus luteum size between non-pregnant and pregnant cows is shown in Fig. 1. In the first part of the studied period (up to day 6) the corpus luteum size was similar in both groups. In the second part of the period, from day 7 onwards, the CL volume tended to be 
larger in the pregnant cows, although the differences were significant only in specific days. Thus, from day 6 to 9 , the growth of the CL was faster in the pregnant cows than in the non-pregnant group ( $117 \%$ vs. $37 \%$ of change, respectively). On day 9 differences between the groups were significant (NP group: $5137.3 \pm 643.9 \mathrm{~mm}^{3}$ vs P group: $8670.8 \pm 1341.6 \mathrm{~mm}^{3}$; $P<0.05)$. The difference between both groups remained constant from day 10 to 12 . Only on day 13, the difference was significant between both groups $\left(8637.7 \pm 1175.1 \mathrm{~mm}^{3}\right.$ vs. $\left.4856.5 \pm 514.6 \mathrm{~mm}^{3}, P<0.01\right)$. After day 19 , both groups differed significantly, indicating the luteal regression in non-pregnant cows. In this group, CL volume decreased by $29 \%$ from day 19 to 22 , especially between days 20 and 21 (41\%) $(P<0.05$ and $P<0.001$, respectively).

Conversely, the CL volume remained stable in the pregnant group during these days.

\section{Fig. 1}

Comparison of the volume of the corpus luteum $\left(\mathrm{mm}^{3}\right)$ between pregnant and non-pregnant cows. CL, (corpus luteum); P, (pregnant); NP, (non-pregnant). Asterisks indicate significant differences between both groups for days $* P<0.05$; ** $P<0.01$; *** $P<0.001$.

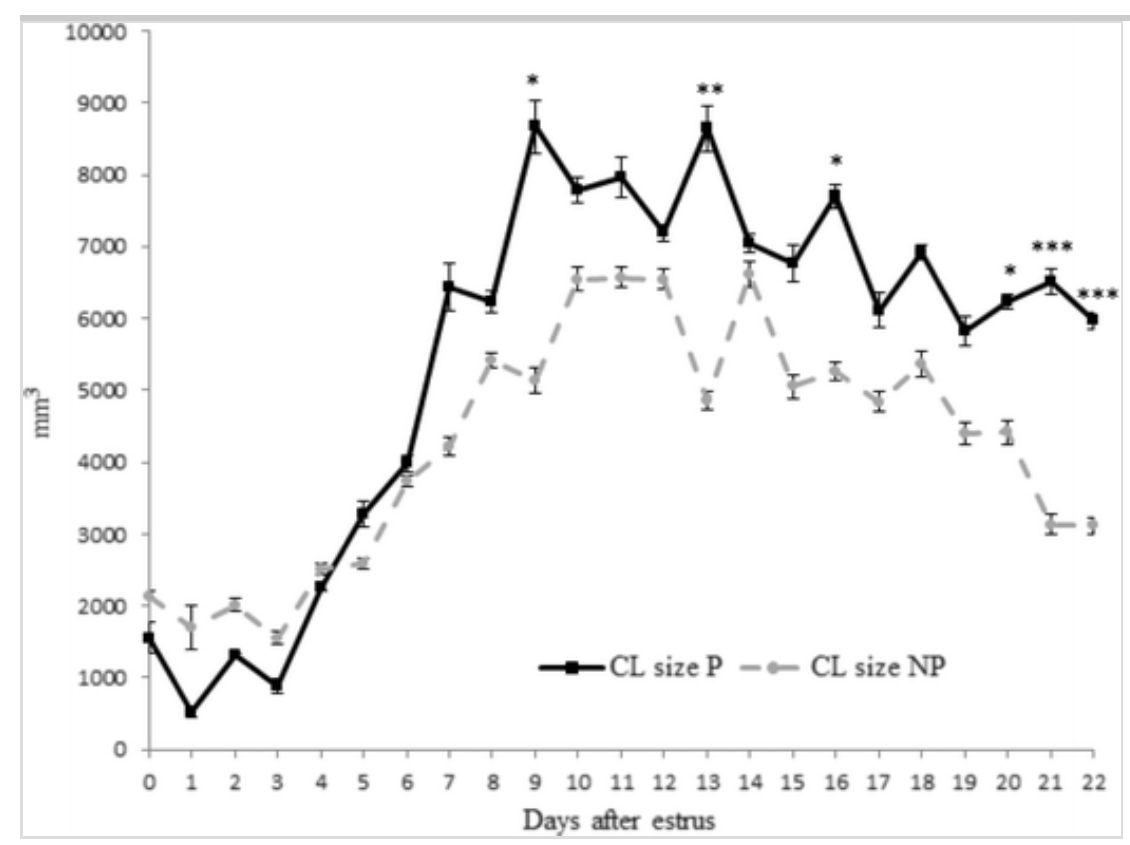

The comparison of the plasma progesterone concentration between non-pregnant and pregnant cows is shown in Fig. 2. Up to day 13, the progesterone concentration was similar between both groups, with almost identical growth rate (2575\% in the NP group vs. $3036 \%$ in the P group). Only after day 13 , both groups started to differ, with the pregnant group achieving higher values, but with great fluctuations. Thus values on day 14 were $9.8 \pm 1.2 \mathrm{ng} / \mathrm{ml}$ in pregnant group vs. $6.2 \pm 0.7 \mathrm{ng} / \mathrm{ml}$ in non-pregnant $(P<0.05)$, and on day 16 were $5.6 \pm 0.8 \mathrm{ng} / \mathrm{ml}$ and $8.7 \pm 1.0 \mathrm{ng} / \mathrm{ml}$ respectively $(P<0.05)$, but differences were not significant in other days. From day 18 onwards, both groups differed significantly. In the non-pregnant group, the plasma progesterone concentration decreased consistently ( $52 \%$ of decrease from day 17 to 22 ). On the other hand, the progesterone concentration in the pregnant cows remained stable. On day 22, the concentration was $8.2 \pm 1.1 \mathrm{ng} / \mathrm{ml}$ vs. $3.2 \pm 0.8 \mathrm{ng} / \mathrm{ml}$ (P group vs. NP group). 


\section{Fig. 2}

Comparison of plasma progesterone concentration $(\mathrm{ng} / \mathrm{ml})$ between pregnant and non-pregnant cows. P4, (progesterone); P, (pregnant); NP, (non-pregnant). Asterisks indicate significant differences between both groups for days $* P<0.05$; $^{*} P<0.01$; *** $P<0.001$.

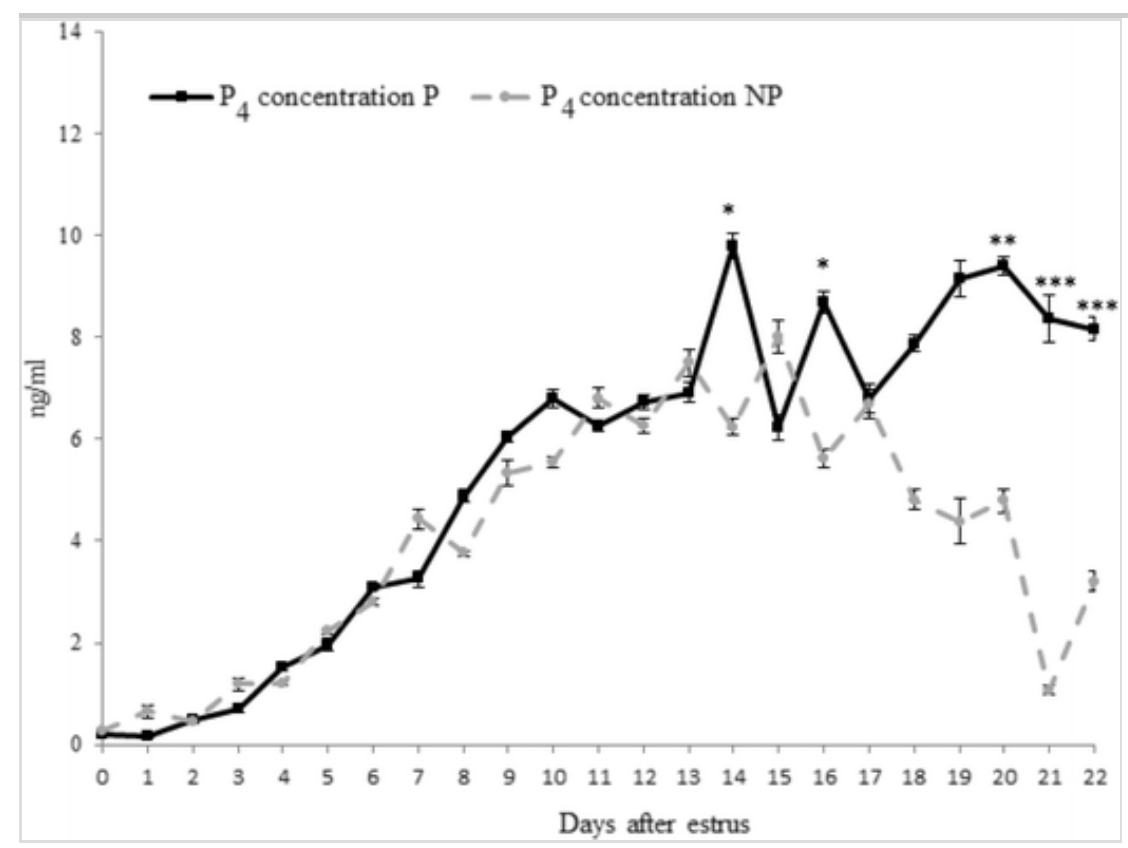

Studying the correlations (from the day 0 to 22 ) and after splitting the data according the two proposed limits (day 11 or day 17). We found a significant general moderate correlation in the non-pregnant group between the volume of the corpus luteum and the plasma progesterone concentration $(r=0.50, \mathrm{P}<0.001)$. The correlation from day 0 to 11 was $r=0.59(\mathrm{P}<0.001)$ and from day 12 to 23 was $r=0.38(\mathrm{P}<0.001)$, whereas the correlation from day 0 to 17 was $r=0.527(\mathrm{P}<0.001)$ and from day 18 to 23 was $r=0.402(\mathrm{P}<0.001)$. In the pregnant group, the general correlation between the $\mathrm{CL}$ volume and the plasma progesterone concentration was $r=0.37(\mathrm{P}<0.001)$. The correlation from day 0 to 11 was $r=0.63(\mathrm{P}<0.001)$ and from day 12 to 23 was $r=0.12(\mathrm{P}<0.05)$. The correlation from day 0 to 17 was $r=0.482(\mathrm{P}<0.001)$ and from day 18 to 23 was $r=0.15(\mathrm{P}<0.05)$.

\section{Discussion}

This study allows to comparing the evolution of the CL volume in non-pregnant cows and early pregnant cows, without pharmacological induction of ovulation or luteolysis. Our results show that the CL volume measurements by ultrasonography during the developing phase increased in both groups (until day 9). These results reflect the observations supported by histological exams of the CL (Singh et al. 1997). During the period of the luteal growth, the histological study of the CL showed a hypertrophy of the luteal cells and a high presence of the blood vascular components in the CL. This increase in the luteal cells size have been shown to parallel progesterone secretion. As we have observed during the CL growth, the plasma progesterone concentration increases in both groups, reaching a maximum peak in the pregnant group on day $14(9.8 \pm 1.2 \mathrm{ng} / \mathrm{ml})$, and on day 15 in the non-pregnant group $(8.0 \pm 1.3 \mathrm{ng} / \mathrm{ml})$. Around day 14 , the luteal volume tended to decrease in both groups, although this drop was less evident in the pregnant group and the CL volume stabilized in the last days. This evolution of the CL volume reflect the degenerative changes that suffer the CL including regression of capillaries, increased 
connective tissue, regression and loss of luteal parenchymal cells (Tamura et al. 2008) reflected in a drop in CL volume by echographic exam and in a parallel diminution of the plasma progesterone concentration (Singh et al. 1997). Contrarily, other studies reported that the diminution of plasma progesterone was more rapid than the estimated CL volume regression (Herzog et al. 2011).

In the case of the pregnant group, the CL volume remained stable during these days. The presence of a conceptus produces interferon-tau, which inhibits the secretion of uterine $\mathrm{PGF}_{2 \alpha}$ (Thatcher et al. 2001) from the day 15 to 17 of gestation (Wolf et al. 2003). Thus, the pregnant animals do not experience an increase in the pulsatile release of $\mathrm{PGF}_{2 \alpha_{-}^{-}}$, and the CL is maintained for a further 200 days of pregnancy (Niswender et al. 2000). But a fail in the maintaining of this mechanism that was initiated but not sustained resulted in an early embryonic loss (Humblot 2001). A study reported that embryonic loss did not affect the plasma concentration progesterone or the luteal area, being similar in the pregnant cows and cows with apparent embryonic loss (Herzog et al. 2011).

It is interesting to remark the different pattern of the evolution of the CL volume and the progesterone concentration in physiological conditions. The progesterone concentration during the developing phase increased more sharply than the CL volume whereas, the drop in the CL volume was much faster than the decrease in plasma progesterone during the luteal regression phase. Our results differ from other authors (Kamimura et al. 1993), who described that the CL volume and plasma progesterone increased similarly during the developing phase, while CL volume decreased more slowly in the luteal regression phase. Contrarily, other studies reported that the diminution of plasma progesterone was more rapid (form day 13) than the estimated CL area regression (from day 18) (Herzog et al. 2011). Moreover, these authors (Kamimura et al. 1993 ) indicated that the peak progesterone concentrations and CL volumes level were smaller after the first ovulation, compared with the second and third ovulations (progesterone values: $5.9 \pm 2.0,6.8 \pm 1.7$ and $7.6 \pm 1.5 \mathrm{ng} / \mathrm{ml}$; CL volume: $7760 \pm 2730,8780 \pm 3680$ and $10,110 \pm 3340 \mathrm{~mm}^{3}$, respectively). The present study reports on the first ovulation, and the progesterone peak was higher $(8.0 \pm 1.3 \mathrm{ng} / \mathrm{ml})$ than any other concentration reported by these authors. Contrarily, we obtained a smaller CL peak $\left(6572.8 \pm 605.6 \mathrm{~mm}^{3}\right)$.

We have noted several changes in the correlations between the CL volume and the plasma progesterone concentration in different periods of the cycle, slightly higher in the first part (up to day 17). Our results differ with other study that studied a possible relationship between CL size and progesterone levels in the developing and regression periods (Assey et al. 1993). These authors found a correlation coefficient of 0.42 during the developing phase, while was lower and non-significant ( 0.26 during the regressing phase). In that case, the luteolysis process was induced by cloprostenol, and the regression phase was considered from the cloprostenol administration to the ovulation day (the day that the largest follicle disappeared) and the developing phase from day 1 to 7 . The reason that caused the difference between our results and those results could be the cloprostenol administration, which could cause a delay or absence of the progesterone decrease, due to either incomplete luteolysis or to excess production of progesterone from sources other than the regressing CL (Callesen et al. 1987).

In the pregnant group, the general correlation (from day 0 to 23) was lower than in non-pregnant cows, but during the developing phase this value was similar in both groups. Whereas progesterone concentrations were similar between both groups, they started to show higher 
values for pregnant cows after day 13 , and this trend clearly defined after day 17 . However, CL size started to differ earlier (first significant difference by day 9). An increase in the differences between pregnant and non-pregnant cows in CL size and progesterone was also found in beef heifers (Charolais and Limousin crossbreds) after day 18 post-AI (Scully et al. 2015).

\section{Conclusions}

In conclusion, the results of the present study validate that the ultrasonography could be useful for assessing the presence of a functional CL. It is an easy and, reliable method for the early assessment of CL functionality in cows after AI. This study is the basis for a next one assessing the predictive value of this technique for early diagnosis of pregnancy in cows.

\section{Acknowledgments}

Cristina Gómez Seco was supported by Junta de Castilla y León program EDU/1083/2013, supported by EDRF (EU).

Compliance with ethical standards

\section{Conflict of interest \\ AQ1}

The authors declare no conflicts of interest with respect to the research, authorship, and/or publication of this article.

Funding sources This research did not receive any specific grant from funding agencies in the public, commercial, or not-for-profit sectors.

\section{References}

AQ2

Assey RJ, Purwantara B, Greve T, Hyttel P, Schmidt MH (1993) Corpus Luteum size and plasma progesterone levels in cattle after cloprostenol-induced luteolysis. Theriogenology 39:1321-1330

Bazer FW, Wu G, Spencer TE, Johnson GA, Burghardt RC, Bayless K (2010) Novel pathways for implantation and establishment and maintenance of pregnancy in mammals. Mol Hum Reprod 16:135-152

Callesen H, Greve T, Hyttel P (1987) Premature ovulations in superovulated cattle. Theriogenology 28:155-166

Fricke PM (2002) Scanning the future-ultrasonography as a reproductive management tool for dairy cattle. J Dairy Sci 85:1918-1926

Galvão KN, Sá Filho MF, Santos JEP (2007) Reducing the interval from presynchronization to initiation of timed artificial insemination improves fertility in dairy cows. J Dairy Sci $90: 4212-4218$

Ginther OJ (2014) How ultrasound technologies have expanded and revolutionized research in reproduction in large animals. Theriogenology 81:112-125 
Ginther OJ, Shrestha HK, Beg MA (2010) Circulating hormone concentrations within a pulse of a metabolite of prostaglandin F2 $\alpha$ during preluteolysis and early luteolysis in heifers.

Anim Reprod Sci 122:253-258

Hanzen CH, Pieterse M, Scenczi O, Drost M (2000) Relative accuracy of the identification of ovarian structures in the cow by ultrasonography and palpation per rectum. Vet $\mathrm{J}$ 159:161-170

Herzog K, Voss C, Kastelic JP, Beindorff N, Paul V, Niemann H, Bollwein H (2011) Luteal blood flow increases during the first three weeks of pregnancy in lactating dairy cows.

Theriogenology 75:549-554

Humblot P (2001) Use of pregnancy specific proteins and progesterone assays to monitor pregnancy and determine the timing, frequencies and sources of embryonic mortality in ruminants. Theriogenology 56:1417-1433

Kamimura S, Ohgi T, Takahashi M, Tsukamoto T (1993) Postpartum resumption of ovarian activity and uterine involution monitored by ultrasonography in Holstein cows. J Vet Med Sci Jpn Soc Vet Sci 55:643-647

López-Gatius F, García-Ispierto I (2010) Ultrasound and endocrine findings that help to assess the risk of late embryo/early foetal loss by non-infectious cause in dairy cattle. Reprod Domest Anim Zuchthyg 45(Suppl 3):15-24

Mann GE (2009) Corpus Luteum size and plasma progesterone concentration in cows. Anim Reprod Sci 115:296-299

Niswender GD, Juengel JL, Silva PJ, Rollyson MK, McIntush EW (2000) Mechanisms controlling the function and life span of the corpus luteum. Physiol Rev 80:1-29

Peukert-Adam I, Sehwarz R, Boos A, Gasse I, Grunert E (1987) The large lutealeells of luteinized follicular cysts and corpora lutea periodica in cows. A cytometric study. Zentralb1 Veterinarmed $A 34: 602608$

Pieterse MC, Taverne MA, Kruip TA, Willemse AH (1990) Detection of corpora lutea and follicles in cows: a comparison of transvaginal ultrasonography and rectal palpation. Vet Rec 126:552-554

Sewlly S, Butler ST, Kelly AK, Evans ACO, Lonergan P, Crowe MA (2014) Early pregnaney diagnosis on days 18 to 21 postinsemination using high-resolution imaging in laetating dairy eows. J Dairy Sei 97:3542 3557

Scully S, Evans ACO, Carter F, Duffy P, Lonergan P, Crowe MA (2015) Ultrasound monitoring of blood flow and echotexture of the corpus luteum and uterus during early pregnancy of beef heifers. Theriogenology 83:449-458

Simersky R, Swaczynova J, Morris DA, Franek M, Strnad M (2007) Development of an ELISA-based kit for the on-farm determination of progesterone in milk. Vet Med (Praha) $52: 19-28$ 
Singh J, Pierson RA, Adams GP (1997) Ultrasound image attributes of the bovine corpus luteum: structural and functional correlates. J Reprod Fertil 109:35-44

Spell AR, Beal WE, Corah LR, Lamb GC (2001) Evaluating recipient and embryo factors that affect pregnancy rates of embryo transfer in beef cattle. Theriogenology 56:287-297

Stevenson JS, Cartmill JA, Hensley BA, El-Zarkouny SZ (2003) Conception rates of dairy cows following early not-pregnant diagnosis by ultrasonography and subsequent treatments with shortened ovsynch protocol. Theriogenology 60:475-483

Tamura H, Takasaki A, Taniguchi K, Matsuoka A, Shimamura K, Sugino N (2008) Changes in blood-flow impedance of the human corpus luteum throughout the luteal phase and during early pregnancy. Fertil Steril 90:2334-2339

Thatcher WW, Guzeloglu A, Mattos R, Binelli M, Hansen TR, Pru JK (2001) Uterineconceptus interactions and reproductive failure in cattle. Theriogenology 56:1435-1450

Waldmann A, Raud A (2016) Comparison of a lateral flow milk progesterone test with enzyme immunoassay as an aid for reproductive status determination in cows. Vet Rec $178: 260-260$

Wilsdorf LJ, Keisler DH, Poock SE, Lamberson WR, Escalante RC, Lucy MC (2016) Short communication: test for nonpregnancy in dairy cows based on plasma progesterone concentrations before and after timed artificial insemination. J Dairy Sci 99:5858-5865

Wolf E, Arnold GJ, Bauersachs S, Beier HM, Blum H, Einspanier R, Fröhlich T, Herrler A, Hiendleder S, Kölle S, Prelle K, Reichenbach H-D, Stojkovic M, Wenigerkind H, Sinowatz F (2003) Embryo-maternal communication in bovine - strategies for deciphering a complex cross-talk. Reprod Domest Anim Zuchthyg 38:276-289

Zdunczyk S, Janowski T, Raś A, Barański W (2009) Accuracy of ultrasonography and rectal palpation in the diagnosis of silent heat in cows compared to plasma progesterone concentration. Bull Vet Inst Pulawy 53:407-410

Zia AI, Syaifudin ARM, Mukhopadhyay SC, Yu PL, Al-Bahadly IH, Kosel J, Gooneratne C (2012) Sensor and instrumentation for progesterone detection. In: 2012 I.E. international instrumentation and measurement technology conference proceedings. Presented at the 2012 I.E. international instrumentation and measurement technology conference proceedings, pp. $1220-1225$ 